\title{
Identification of odour-active compounds in muscle of brown trout (Salmo trutta) as affected by dietary lipid sources
}

\author{
Thierry Sérot ${ }^{1 *}$, Christelle Regost $^{2}$, Jacqueline Arzel ${ }^{2}$
}

\author{
${ }^{1}$ Ecole Nationale d'Ingénieurs des Techniques et Industries Agro-Alimentaires, Laboratoire de Biochimie \\ Industrielle Alimentaire, Rue de la Géraudière, BP 82225, F-44322 Nantes Cedex 3, France \\ ${ }^{2}$ Laboratoire de Nutrition des Poissons, Unité mixte INRA-IFREMER, Institut Français de Recherche et \\ d'Exploitation de la Mer, Centre de Brest, BP 70, F-29280 Plouzané, France \\ *: Corresponding author : email: Thierry Sérot tserot@ifremer.fr
}

\begin{abstract}
The effect of fatty acid composition on odour-active compounds in brown trout (Salmo trutta) muscle was evaluated. The fillets were obtained from three groups of fish fed experimental diets containing either fish oil (FO), soybean oil (SO) or linseed oil (LO). Muscle fatty acid composition was shown to be influenced by diet. Thirty-one odorous compounds were detected by gas chromatography/olfactometry (frequency-of-detection method). Most of these compounds were formed by the oxidation of unsaturated fatty acids. Independently of diet, (E)-2-pentenal, (E)-2-pentenol and (E)-2-hexenol contribute strongly to the odour of brown trout. (E,Z)-2,4-Heptadienal was detected with high frequency in fish fed diets containing high levels of n-3 PUFAs (FO and LO groups). Hexanal, (E)2-hexenal and 2-nonanol seem to contribute most to the odour of fish fed diets containing vegetable oils. Many odorous compounds were derived from the oxidation of mono- and di-unsaturated fatty acids, which could be promoted by high levels of PUFAs.
\end{abstract}

Keywords: brown trout; odour-active compounds; olfactometry; vegetable oils 


\section{INTRODUCTION}

Substitution of vegetable oil for fish oil in salmonid diets is a more and more widespread practice in aquaculture. The main reason is a weak availability of fish oil. Since the fatty composition of fish muscle was affected by dietary lipid composition 1, 2,3,4 studies have carried out on the effects of dietary lipid source on the oxidative stability 5 and sensory characteristics of fish muscle 6,7,8. The most of these works showed that vegetable oil improved the sensory quality of fish muscle. According to Skonberg et al ${ }^{6}$ panellists tend to prefer fish fed a diet containing sunflower oil to fish fed a diet containing herring oil, becauseherring oil fish exhibited a "fishier" aroma than the sunflower fish.In fact the main source of aroma in fish muscle are the oxidative deterioration of polyunsaturated fatty acid (PUFA) 9,10. Typical aroma of fish fresh is related to volatile compounds arising from enzymatic oxidation of PUFA, while enzymatic and chemical oxidation (autoxidation) are the source of volatile compounds arising during chilled storage of fish 11. Altering the fatty composition of fish muscle can affect its flavor characteristics. However, while several studies have conducted into the effects of diets on the volatiles composition of mammalian meat $12,13,14$, few works are concerned in fish muscle. These studies mainly concerned the comparison of aroma compounds from wild and farmed fish but these results are contradictory. Suyama et al. ${ }^{15}$ have shown that volatile compounds compositions of wild and farmed ayu were similar but the concentration was lower in farmed fish than in wild fish. However, Hirano et al ${ }^{16}$ found that there was no difference of concentration and composition of volatile compounds between wild and farmed ayu. In a previous work 17, using an olfactometric method (detection frequency) we have shown that the main odour-active compounds of muscle turbot was affected by origin of dietary lipids. During this survey thirty-one odorous compounds detected in turbot muscle extracts, among these 23 compounds were formed during oxidation of unsaturated fatty acids. (E,Z)-2,6-nonadienal, $(E)$-2-pentenal and $(E, E)-1,3-(Z)-5$-octatriene seem to strongly contribute to the odour of turbot fed diets containing high level of n-3 PUFA (fish oil and linseed oil). On the other hand the high level of n-6 PUFA was largely responsible of the high detection frequency of hexanal and decanal in turbot fed a diet containing soybean oil.

The present paper examine the odour-active compounds of flesh from brown trout fed experimental diets differing in PUFA content, provided by fish oil, soybean oil or linseed oil,. The fatty acid composition will be determinated by gas chromatography analysis and odour-active compounds characterized by gas chromatography/olfactometry (GC/O). Data are presented showing the relationships between the fatty acid composition and the perception of odour-active compounds.

\section{MATERIAL AND METHODS}

\section{Chemicals}

Dichloromethane (for analyses), chloroform, hexane and pentane (GC quality) were purchased from Merck (Nogent sur Marne, France). Methanol (HPLC quality) were purchased from SdS (Peypin, France). Dichloromethane (GC quality), all standard compounds, $\mathrm{BF}_{3} /$ methanol and Tricosanoic acid were purchased from Sigma-Aldrich (l'Isle d'Abeau, France). 


\section{Experimental diets}

Three experimental diets with 15\% added lipid: fish oil (FO), soybean oil (SO) or linseed oil (LO) were formulated to be isonitrogenous (53.5\% of dry matter) and isolipidic.(20\% of dry matter). Diets were texturized industrially in the form of $9 \mathrm{~mm}$ granules by Le Gouessant Aquaculture (Lamballe, France). Fatty acid compositions of diets are reported in Table 1.

\section{Growth study}

The growth trial was conducted on brown trout reared in seawater in the experimental facilities of Salmoniculture Experimentale Mixte INRA- IFREMER (SEMII, Camaret, France). Each diet was fed to triplicate of 78 fish (initial body weight: $1484 \pm 7$ g; mean \pm sd) reared in $60 \mathrm{~m}^{3}$ floating cages. Fish were fed ad libitum 3 times a day for 11 weeks with the experimental diets. At the end of the experiment, 3 fish per cage were withdrawn for measurements of volatile compounds and 3 fish per cage were withdrawn for lipid and fatty acid analysis. The fish were filleted and stored without skin at $-80^{\circ} \mathrm{C}$.

Table 1: Fatty acid composition of experimental diets (\% of total methyl esters).

\begin{tabular}{lccc}
\hline & \multicolumn{3}{c}{ Régimes expérimentaux } \\
\cline { 2 - 4 }$\sum$ Saturated & HP & HS & HL \\
\cline { 2 - 4 } $18: 1 n-9$ & $\mathbf{2 7 . 0}$ & $\mathbf{1 7 . 5}$ & $\mathbf{1 8 . 3}$ \\
$22: 1 n-11$ & 15.0 & 19.3 & 15.6 \\
$\sum$ Monunsaturated & 6.0 & 1.9 & 3.5 \\
18:2n-6 & $\mathbf{3 7 . 1}$ & $\mathbf{2 6 . 9}$ & $\mathbf{2 8 . 0}$ \\
18:3n-6 & 7.1 & 39.1 & 12.1 \\
$20: 2 n-6$ & 0.2 & - & 0.2 \\
$20: 4 n-6$ & 0.4 & 0.1 & 0.2 \\
$\sum$ n-6 & 0.7 & 0.2 & 0.4 \\
18:3n-3 & $\mathbf{8 . 4}$ & $\mathbf{3 9 . 4}$ & $\mathbf{1 2 . 9}$ \\
$18: 4 n-3$ & 1.4 & 9.9 & 27.7 \\
$20: 3 n-3$ & 2.0 & 0.4 & 1.1 \\
20:4n-3 & 0.2 & - & 0.1 \\
$20: 5 n-3$ & 0.6 & - & - \\
$22: 5 n-3$ & 8.5 & 2.1 & 4.4 \\
$22: 6 n-3$ & 1.5 & 0.3 & 0.7 \\
$\sum$ n-3 & 13.3 & 3.5 & 6.8 \\
$\mathbf{n}-3 / \mathbf{n}-\mathbf{6}$ & $\mathbf{2 7 . 5}$ & $\mathbf{1 6 . 2}$ & $\mathbf{4 0 . 8}$ \\
\hline
\end{tabular}




\section{Total lipid extraction and fatty acid analysis}

Fillets were minced in a blender and total lipids were extracted from $6 \mathrm{~g}$ of muscle. Total lipid muscle was extracted according to Folch et al. $^{18}$, chloroform being replaced by dichloromethane. Methyl esters of fatty acids were prepared as described by Morrison and Smith ${ }^{19}$ and stored at $-20^{\circ} \mathrm{C}$ until analysis.

Fatty acids were analysed by gas chromatography (GC) using a BPX 70 capillary column (25 $\mathrm{m} \times 0.22 \mathrm{~mm}$ i.d $\times 0.25 \mu \mathrm{m}$ film thickness, (SGE Europe, Ldt). Analyses were performed on an Autosystem Perkin-Elmer. Each extract $(0.5 \mu \mathrm{l})$ was injected in splitless mode. The flow rate of carrier gas was $1 \mathrm{~mL} / \mathrm{min}$. The injector and flame ionization detector (FID) temperatures were set to 220 and $260^{\circ} \mathrm{C}$ respectively. Oven temperature was raised from $50^{\circ} \mathrm{C}$ to $180^{\circ} \mathrm{C}$ at a rate of $15^{\circ} \mathrm{C} / \mathrm{min}$, maintained for $5 \mathrm{~min}$ at this temperature then raised to $220^{\circ} \mathrm{C}$ at a rate of $3^{\circ} \mathrm{C} / \mathrm{min}$. Data acquisition and handling were carried out by connecting the chromatograph to a PE Nelson computer. The individual fatty methyl esters were identified by comparison of their retention times with those of authentic standard mixtures. The results on individual fatty acid composition were expressed as percent of total identified fatty acid methyl esters.

\section{Volatile compounds extraction and analysis Reduced pressure steam distillation}

Reduced pressure steam distillation was performed in a low-pressure distillation apparatus modified from the one designed by Forss and Holloway ${ }^{20}$ as previously described ${ }^{21}$. Approximately $250 \mathrm{~g}$ of muscle were minced in a blender. $200 \mathrm{~g}$ of minced muscle, $600 \mathrm{~mL}$ of ultrapure water and $50 \mathrm{~g}$ of $\mathrm{NaCl}$ were transferred into a $6 \mathrm{~L}$ round bottom flask maintained at $30^{\circ} \mathrm{C}$. Distillation was continued for 4 hours under a pressure of 5 mbar until no water is present in the flask. Most of the volatile compounds were collected into a $4 \mathrm{~L}$ round bottom by means of condensers maintained at $-1^{\circ} \mathrm{C}$. The more volatile compounds were collected in traps refrigerated with liquid nitrogen. After distillation, the contents of $4 \mathrm{~L}$ flask and traps were pooled then extracted by $50 \mathrm{~mL}$ of freshly distilled dichloromethane at $0^{\circ} \mathrm{C}$ with magnetic stirring during 15 min. Operation was repeated three times. After dehydration by anhydrous sodium sulphate, the organic extract was reduced to $5 \mathrm{~mL}$ in a Kuderna-Danish concentrator and to $200 \mu \mathrm{l}$ under a gentle stream of nitrogen. The whole process was repeated 3 times for each trout diet batch. The extracts were then stored at $-20^{\circ} \mathrm{C}$ in glass vial before analysis.

\section{Sensory analysis/ representativity of the extracts Pane.}

The panel was composed of 10 assessors of our department ( 6 females and 4 males; between 25 and 45 years old), previously trained in odour recognition, sensory evaluation techniques and with experience in gas chromatography/olfactometry.

Sample preparation and presentation. The fillets of trout were diced, then put in $100 \mathrm{~mL}$ black coded flasks before to be presented to the panel. An aliquot of each of volatile compounds extracts was adsorbed on cardboard smelling strip (ref: 7140 B.P.S.I., GrangerVeyron, Lyas, France) and after 30s (time necessary for solvent evaporation) the extremities of the strips were cut and placed in dark coded flasks and presented to the panel after $30 \mathrm{~min}$.

Descriptive analysis of trout fillets and volatile extracts. The panel was asked to describe the odour of fillets or extracts, by choosing 5 attributes ${ }^{22}$.

Similarity evaluation of odour of muscle and of volatile extracts. Results of olfactometric method are more reliable if the odour of the extracts resembles closely that of the muscle of 
trout submitted for extraction, therefore the odour representativeness of extracts was evaluated with a similarity test ${ }^{23}$. Panellists were asked to smell the odour of muscle and then the odour of corresponding extracts. They had to place the extracts on a $100 \mathrm{~mm}$ unstructured scale, anchored with «far from the muscle odour» on the left and «near to the muscle odour» on the right ${ }^{24,25}$. The positions of the extracts on the scale were read as distance in millimetre from the left anchor.

\section{Gas chromatography/mass spectrometry (GC/MS).}

GC/MS system consisted of an HP5890 II gas chromatograph and an HP5971 mass selective detector (Hewlett-Packard Co., Palo Alto, CA). Each extract $(1 \mu \mathrm{L})$ was injected in the splitless mode $\left(250^{\circ} \mathrm{C}\right.$ injector temperature) into a capillary column (DBWax, $30 \mathrm{~m}$ length $\mathrm{x}$ $0.32 \mathrm{~mm}$ i.d. x $0.5 \mu \mathrm{m}$ film thickness, J\&W Scientific, Folsom, CA). The flow rate of carrier gas (helium) was $1 \mathrm{~mL} / \mathrm{min}$. Oven temperature was programmed from $50{ }^{\circ} \mathrm{C}$ to $180{ }^{\circ} \mathrm{C}$ at a rate of $5{ }^{\circ} \mathrm{C} / \mathrm{min}$ and then to $260{ }^{\circ} \mathrm{C}$ at a rate of $10{ }^{\circ} \mathrm{C} / \mathrm{min}$. Masse selective detector conditions were as follow: ion source temperature, $180{ }^{\circ} \mathrm{C}$; ionization energy, $70 \mathrm{eV}$; mass range, 30-300 amu., electron multiplier voltage, $2100 \mathrm{~V}$ and scan rate, $2 \mathrm{~s}^{-1}$. Compounds identifications were based on comparison of GC retention indices (RI) ${ }^{26}$, with those of authentic standards or with previously published literature, comparison of their mass spectra with standard MS spectra database: NBS 75K and internal library of the laboratory .

\section{Gas chromatography-flame detection-Olfactometry (GC-FID-O)}

The GC-FID-O system consisted of 3400 Star GC (Varian Palo Alto, CA), equipped with a FID and a sniffing port supplied with humidified air at $40{ }^{\circ} \mathrm{C}$. GC effluent was split 1:1 between the FID and sniffing port. Each extract $(4 \mu \mathrm{L})$ was injected in the splitless mode (injector temperature: $250^{\circ} \mathrm{C}$ ) into a capillary column (DBWax, $30 \mathrm{~m}$ length x $0.32 \mathrm{~mm}$ i.d. $\mathrm{x}$ $0.5 \mu \mathrm{m}$ film thickness, J\&W Scientific, Folsom, CA). The flow rate of carrier gas (helium) was $1 \mathrm{~mL} / \mathrm{min}$. Oven temperature was programmed from $50{ }^{\circ} \mathrm{C}$ to $180{ }^{\circ} \mathrm{C}$ at a rate of 5 ${ }^{\circ} \mathrm{C} / \mathrm{min}$, then to $250^{\circ} \mathrm{C}$ at a rate of $10^{\circ} \mathrm{C} / \mathrm{min}$. The FID detector was set to $280^{\circ} \mathrm{C}$.

\section{Frequency of detection method (FDT)}

The same panel of 8 judges ${ }^{27}$ previously selected for sensory analysis was used for GC/O. Sniffing of the chromatogram was divided into two parts of $17 \mathrm{~min}$. Each judge participated in the sniffing of both parts, but during two distinct sessions to remain alert. The panellists were asked to assign odour properties to each odorant area detected. Detection of an odour at the sniffing port by fewer than 3 of 10 assessors was considered to be noise ${ }^{10}$. The 10 individual aromagrams were summed, yielding the final aromagram (detection frequency versus RI).

\section{Statistical analysis}

Data were subjected to one-way analysis of variance to test the effects of experimental diets. In case where significant difference occurred (significance level $=0.05$ ), the Newman-Keuls test was used to compare the means. All statistical tests were performed using the STATITCF software (1998) (ITCF, Paris, France). 


\section{Results and discussion}

\section{Lipid and main fatty acid composition.}

No significant difference due to dietary treatment was observed concerning total lipid content of trout muscle. The lipid content was $6.4 \% \pm 0.4 \%, 6.5 \% \pm 0.1 \%$, and $6.0 \% \pm 03 \%$ in the muscle of trout fed a diet FO, SO and LO respectively. Fatty acid composition of trout muscle is summarized in Table 2. Muscle of fish fed FO diet was mainly characterized by high levels of 20:5n-3, 22:5 n-3 and 22:6n-3 and by a ratio n-3/n-6 higher than in muscle of fish fed diet containing vegetable oils. Muscle of fish fed SO diet is characterized by a high level of n-6 PUFA, mainly due to a high level of $18: 2 n-6$, and by a very low ratio n-3/n-6. Fatty acid composition of muscle of fish fed LO diet was characterized by a higher level of n-3 PUFA than muscle of fish fed SO and FO diets due to a high percent of 18:3n-3 supplied by linseed oil. Nevertheless, 20:5n-3 and 22:6n-3 levels of fish fed LO diet are near to those of fish fed SO diet and lower than those of fish fed FO diet. These results are similar to those obtained previously with turbot 17 . They show that fatty acid composition of turbot muscle reflected dietary fatty acid composition according, to the previous studies carried out on the substitution of vegetable oils for fish oils in diets ${ }^{1,3,4,7}$.

Table 2: .Fatty acid composition of muscle of trout (\% of total methyl esters).

\begin{tabular}{|c|c|c|c|}
\hline & \multicolumn{3}{|c|}{ Experimental Diets } \\
\hline & FO & $\mathrm{SO}$ & LO \\
\hline$\Sigma$ Saturated & $24.5 \pm 0.3^{\mathrm{a}}$ & $20.8 \pm 0.3^{b}$ & $20.3 \pm 0.3^{b}$ \\
\hline 18:1n-9 & $19.0 \pm 0.4^{\mathrm{b}}$ & $21.8 \pm 0.3^{\mathrm{a}}$ & $19.3 \pm 0.4^{\mathrm{b}}$ \\
\hline$\Sigma$ Monounsaturated & $43.1 \pm 0.6^{\mathrm{a}}$ & $35.5 \pm 0.5^{b}$ & $35.2 \pm 0.5^{\mathrm{b}}$ \\
\hline $18: 2 n-6$ & $7.3 \pm 0.5^{c}$ & $24.8 \pm 0.8^{\mathrm{a}}$ & $13.0 \pm 0.5^{\mathrm{b}}$ \\
\hline 18:3n-6 & $0.3 \pm 0.0^{\mathrm{a}}$ & $0.6 \pm 0.0^{\mathrm{b}}$ & $0.3 \pm 0.0^{\mathrm{a}}$ \\
\hline $20: 2 n-6$ & $0.6 \pm 0.0^{c}$ & $1.1 \pm 0.0^{\mathrm{a}}$ & $0.7 \pm 0.0^{\mathrm{b}}$ \\
\hline $20: 3 n-6$ & $0.3 \pm 0.0^{\mathrm{c}}$ & $0.9 \pm 0.0^{\mathrm{a}}$ & $0.4 \pm 0.0^{\mathrm{b}}$ \\
\hline $20: 4 n-6$ & $0.6 \pm 0.0^{\mathrm{a}}$ & $0.3 \pm 0.0^{\mathrm{b}}$ & $0.3 \pm 0.0^{\mathrm{b}}$ \\
\hline$\sum n-6$ & $9.1 \pm 0.6^{c}$ & $27.7 \pm 0.8^{\mathrm{a}}$ & $14.7 \pm 0.6^{b}$ \\
\hline 18:3n-3 & $1.6 \pm 0.1^{\mathrm{c}}$ & $5.7 \pm 0.1^{b}$ & $15.2 \pm 0.4^{\mathrm{a}}$ \\
\hline $18: 4 n-3$ & $1.4 \pm 0.0^{\mathrm{a}}$ & $1.1 \pm 0.0^{\mathrm{b}}$ & $1.5 \pm 0.0^{\mathrm{a}}$ \\
\hline $20: 3 n-3$ & $0.2 \pm 0.0^{c}$ & $0.3 \pm 0.0^{\mathrm{b}}$ & $0.8 \pm 0.0^{\mathrm{a}}$ \\
\hline $20: 4 n-3$ & $1.4 \pm 0.0^{\mathrm{b}}$ & $0.9 \pm 0.0^{c}$ & $1.6 \pm 0.0^{\mathrm{a}}$ \\
\hline $20: 5 n-3$ & $4.8 \pm 0.1^{\mathrm{a}}$ & $2.0 \pm 0.1^{\mathrm{c}}$ & $2.8 \pm 0.1^{\mathrm{b}}$ \\
\hline $22: 5 n-3$ & $2.1 \pm 0.0^{\mathrm{a}}$ & $0.9 \pm 0.1^{\mathrm{c}}$ & $1.2 \pm 0.0^{\mathrm{b}}$ \\
\hline $22: 6 n-3$ & $11.8 \pm 0.2^{\mathrm{a}}$ & $5.1 \pm 0.3^{c}$ & $6.7 \pm 0.3^{b}$ \\
\hline$\Sigma n-3$ & $23.3 \pm 0.3^{b}$ & $16.0 \pm 0.4^{c}$ & $29.8 \pm 0.4^{a}$ \\
\hline$n-3 / n-6$ & $2.6 \pm 0.1^{\mathrm{a}}$ & $0.6 \pm 0.0^{c}$ & $2.0 \pm 0.1^{b}$ \\
\hline
\end{tabular}

Values in the same raw with different superscripts are significantly different $(\mathrm{p}<0.05)$. 


\section{Representativeness of the extracts}

According to the panellists the odour of trout muscle was mainly characterized as a fatty fish note whatever the diet treatment (Table 3 ). The green note was also suggested by numerous judges to described the odour of muscle. A salmon-like note was pointed out by more judge in fish fed vegetable oil than in fish fed fish oil. The odour of fish fed diets LO and FO was described by a fishy note by 6 judges while only 2 judges perceived this note in muscle of fish fed a diet SO. This difference could be due to an oxidation of lipid in muscle fed diets with high level of n-3 PUFA ${ }^{6}$. Attributes used to characterize the odour of the corresponding extracts were very similar. Fatty fish and green notes were used by numerous judges to characterize the three extracts. Descriptors as boiled potato, cooked fish, alga, phenol were used by panellists to describe odour of muscle and associated volatile extracts.

The coincidence of odour attributes was confirmed by the results of similarity test. On the $100 \mathrm{~mm}$ scale the FO, SO, and LO extracts were situated at $68 \mathrm{~mm}\left(\sigma_{\mathrm{n}-1}=14\right), 62 \mathrm{~mm}\left(\sigma_{\mathrm{n}-1}=9\right)$ and $67 \mathrm{~mm}\left(\sigma_{\mathrm{n}-1}=12\right)$ respectively from left anchor. These results show that similarities are about the same for the three extracts with a good relationship between the odour properties of muscle and those of corresponding extracts ${ }^{23,25}$. The use of an olfactometric method is therefore all made applicable in order to determinate the odour-active compounds of trout muscle.

Table 3. Descriptive analysis of trout muscle and corresponding extracts.

\begin{tabular}{|c|c|c|c|}
\hline & \multicolumn{3}{|c|}{ Attributes } \\
\hline & FO & SO & $\mathrm{LO}$ \\
\hline Muscle & $\begin{array}{l}\text { Fatty fish (9) } \\
\text { Fishy (6) } \\
\text { Green (6), } \\
\text { Salmon-like (4) } \\
\text { Boiled potatoes (3) } \\
\text { Cooked shellfish (3) } \\
\text { Moss, earthy (3) } \\
\text { Alga (3) } \\
\text { Phenol (3) }\end{array}$ & $\begin{array}{l}\text { Fatty fish (8) } \\
\text { Cooked fish (7) } \\
\text { Green (6) } \\
\text { Salmon- like (6) } \\
\text { Boiled potatoes (5) } \\
\text { Fish y (2) }\end{array}$ & $\begin{array}{l}\text { Fatty fish (8) } \\
\text { Green (7) } \\
\text { Fishy (6) } \\
\text { Salmon-like (7) } \\
\text { Boiled potatoes (3) } \\
\text { Cooked shellfish (3) } \\
\text { Phenol (3) }\end{array}$ \\
\hline Extracts & $\begin{array}{l}\text { Green (6) } \\
\text { Fatty fish (6) } \\
\text { Grass, hay (4) } \\
\text { Cooked fish (3) } \\
\text { Salmon-like (3) } \\
\text { Cooked crustacean (3) } \\
\text { Alga (3) } \\
\text { Phenol (3) } \\
\text { Moss, earthy (2) } \\
\text { Boiled potatoes (2) }\end{array}$ & $\begin{array}{l}\text { Fatty fish (8) } \\
\text { Cooked fish (4) } \\
\text { Crustacean (4) } \\
\text { Boiled potatoes (3) } \\
\text { Moss, earthy (3) } \\
\text { Salmon-like (2) } \\
\text { Phenol (2) } \\
\text { Green (2) }\end{array}$ & $\begin{array}{l}\text { Fatty fish (5) } \\
\text { Fishy (5) } \\
\text { Green (4) } \\
\text { Moss, earthy (4) } \\
\text { Phenol (4) } \\
\text { Crustacean (3) } \\
\text { Alga (3) } \\
\text { Boiled potatoes (3) } \\
\text { - }\end{array}$ \\
\hline
\end{tabular}

Show in parenthesis is the number of judges who used this attribute to characterise the odour of fish or extract. 


\section{Olfactometry analysis}

Thirty one odorous compounds were perceived by the judges in at least one of the three extracts according to the olfactometric method and 23 were identified (Table 4). Twenty one odorous compounds were significantly perceived in FO extracts. Twenty three odorous compounds were pointed out by panellists in SO extracts and 26 in LO extracts. The most of the identified odour-active compounds were aldehydes or alcohols resulting from unsaturated fatty acids oxidation (chemical or enzymatic) 11,28 . The lipid-derived aldehydes strongly contribute to the odour of fish 18 , because they have a low detection thresholds 32 . The most perceived odorants in the three extracts were an unsaturated aldehydes, the (E)-2-pentenal and two unsaturated alcohols, the $(E)-2$ penten-1-ol and the $(E)$-2-hexen-1-ol. E-2-pentenal was perceived with a grass-like and green note by 8 judges in FO extracts and by 7 judges in $\mathrm{SO}$ and LO extracts. This compound has been previously described in crayfish 29, oysters 30 and turbot 17. (E)-2-hexen-1-ol was perceived by 7 judges in the three extracts and exhibited a green and moss like odour. (E)-2-penten-1-ol was perceived by 5, 6 and 7 judges in FO, SO and LO extracts respectively and was described as having a strong mushroom-like odour. This compound was considered as one of most odorous in clams 31 and mussel 32. According to Prost et al 10, (E)-2-penten-1-ol contributed partially to the aroma of farmed turbot. In a previous work we have shown that $(E)$-2-hexen-1-ol and $(E)$-2-penten-1-ol were the most odorous compounds in turbot fed diets containing fish oil, soybean oil or linseed oil 17. These three compounds are produced by oxidation of n-3 PUFA 31,35. (E)-2-pentenal is known to be formed either by action of 15-lipoxygenase on n-3 PUFA, mainly 18:3n-3 and 22:6n-3 33 or by oxidative cleavage of 2,4,7-decatrienal, formed during n-3 PUFA oxidation 34,30. Some odour-active compounds were more strongly perceived by panellists in some extracts. So $(E, Z)$-2,4-heptadienal was perceived by 8 judges in FO extract while 6 judges perceived it in LO extract and it was not detected in SO extract. This compound which exhibit a green and cucumber-like odour was described in most seafood products. According to Josephson (1991) 11 this compound is one of the more abundant compounds generated during autoxidation of seafood products. (E,Z)-2,4-heptadienal is formed by oxidation of n-3 polyunsaturated fatty acids but it appears to be derived mainly from hydroperoxydation on carbon-14 of eicosapentaenoic acid 11. The strong contribution of this compound to the odour of muscle of trout fed FO diet could be explained by its higher level of eicosapentaenoic acid concentration that those of muscle of trout fed LO or SO diets. E-2heptenal and octanol were more strongly perceived in extracts from trout fed diet FO and LO than in those from trout fed a diet SO. E-2-heptenal was perceived with a roasted odour by 6 and 5 judges in LO and FO extracts respectively and by 3 judges in SO extracts. This compounds is mainly formed by scission of 12-hydroperoxyde of linoleic acid and of 14hydroperoxyde of arachidonic acid 33. The difference of perception of $E$-2-heptenal is difficult to explained. Indeed even though the content in 20:4 n-6 is raised more in the trout fed a FO diet, the content in 18:2 n-6 is superior in the trout fed LO and SO diets. Octanol, whose perception is slightly more elevated in the FO and LO extracts than in SO extracts, is known to be mainly formed by oxidation of oleic acid 33. This result is also in contradiction with the result of content in oleic acid of trout muscle. It seems therefore, that, in the present case, another explanation that the direct relation between the content in fatty acids and the olfactory perception must be sought-after Hexanal, E-2-hexenal and 2-nonanol are more perceived in muscle of fish fed diets containing vegetable oils, particularly linseed oil, that in muscle of fish fed a FO diet. Hexanal, which was perceived by 4 judges, is generally considered as an off flavour in seafood products, involved in oxidized fish flavour 35. It could 
be used as an indicator of degradation of seafood products and meat from terrestrial animals 36. This compound, that exhibits a grass-like odour, is produced by oxidation of n-6 PUFA. Results of olfactometric analysis could be explained by the occurrence of a higher level of n6 PUFA in fillets of trout fed diets with vegetable oils than in those of trout fed FO diet. E-2hexenal, described with a moss-like odour, was perceived by 7 and 5 judges in trout fed LO and SO diets respectively and by only 3 judges in trout fed FO diet. It is known to be mainly generated from scission of 12 and 13-hydroperoxyde of linolenoic acid 33. A high level of 18:3n-3 in fillets from trout fed LO diet, and to one least degree in fillets from trout fed SO diet could explain the difference of perception of $(E)$-2-hexenal according to diet. 2-nonanol was perceived with a fresh and moss-like odour by 6 and 3 judges in extracts from muscle of trout fed LO and SO diets respectively and not significantly perceived in FO extract. To our knowledge, no information is available on origin of 2-nonanol, however this compound could be formed by oxidation of n-9 monounsaturated fatty acids as other saturated alcohols as heptanol or octanol 28,34. 
Table 4 : Odour-active compounds detected in trout muscle.

\begin{tabular}{|c|c|c|c|c|c|c|}
\hline \multirow[t]{2}{*}{$\mathrm{RI}^{\mathrm{a}}$} & \multirow[t]{2}{*}{ Compound } & \multirow[t]{2}{*}{ Method of identification } & \multirow[t]{2}{*}{ Odour description ${ }^{b}$} & \multicolumn{3}{|c|}{$\begin{array}{l}\text { Detection } \\
\text { frequency }\end{array}$} \\
\hline & & & & FO & SO & $\mathrm{LO}$ \\
\hline 1032 & 1-propanol & MS, RI, standard & solvent & $1^{\mathrm{f}}$ & 4 & $1^{\mathrm{f}}$ \\
\hline 1077 & hexanal & MS, RI, standard, odour ${ }^{\mathrm{c}, \mathrm{d}}$ & grass, green & $2^{f}$ & 5 & 8 \\
\hline 1107 & unidentified & & sulphur & $2^{f}$ & 5 & 5 \\
\hline 1134 & E-2-pentenal & MS, RI, standard & green, grass & 8 & 7 & 7 \\
\hline 1238 & E-2-hexenal & MS, RI, standard & moss, mushroom & 3 & 6 & 7 \\
\hline 1290 & octanal & MS, RI, standard, odour ${ }^{\mathrm{c}, \mathrm{d}}$ & orange, citrus fruit & 4 & 4 & 5 \\
\hline 1300 & E-2-penten-1-ol & MS, RI, standard, odour ${ }^{c}$ & mushroom & 5 & 6 & 7 \\
\hline 1332 & 6-méthyl-5-hepten-3-one & MS, RI, standard & fruity & $0^{f}$ & $1^{\mathrm{f}}$ & 3 \\
\hline 1342 & E-2-heptenal & MS, RI, standard & roasted & 5 & 3 & 6 \\
\hline 1364 & éthyl-pyrazine & MS, RI, odour ${ }^{\mathrm{d}}$ & grilled hazel nut & 4 & 3 & 4 \\
\hline 1373 & E-2-hexen-1-ol & MS, RI, standard & moss, green & 7 & 7 & 7 \\
\hline 1457 & méthional & MS, RI, standard, odour ${ }^{\mathrm{c}, \mathrm{d}}$ & boiled potatoes & 4 & 4 & 4 \\
\hline 1474 & unidentified & & earthy & 3 & $1^{\mathrm{f}}$ & $0^{\mathrm{f}}$ \\
\hline 1482 & (Z, Z)-1, 5-octadien -3- ol & MS, RI, odour & mushroom & $2^{f}$ & $2^{f}$ & 3 \\
\hline 1505 & $(E, E)-2$, 4--heptadienal & MS, RI, standard & green, cucumber & 8 & $2^{f}$ & 6 \\
\hline 1513 & decanal & MS, RI, standard & green & 4 & 5 & 4 \\
\hline 1535 & 2-nonanol & MS, RI, standard & moss, fresh & $2^{\mathrm{f}}$ & 3 & 6 \\
\hline 1553 & E-2-nonenal & MS, RI, standard & rotten, earthy & 5 & 5 & 5 \\
\hline 1556 & octanol & MS, RI, standard & green, floral & 5 & 3 & 5 \\
\hline 1588 & (E, Z)-2, 6-nonadienal & MS, RI, standard, odour ${ }^{\mathrm{c}, \mathrm{d}}$ & green, cucumber & 5 & 6 & 6 \\
\hline 1593 & unidentified & & green, floral & 3 & $1^{\mathrm{f}}$ & $1^{\mathrm{f}}$ \\
\hline 1647 & 2-octen-1-ol & MS, RI, standard, odour ${ }^{\mathrm{c}, \mathrm{d}}$ & green & 4 & 3 & 4 \\
\hline 1665 & 1-nonanol & MS, RI, standard & citrus fruit & 5 & 5 & 6 \\
\hline 1710 & unidentified & & grilled almond & 3 & 3 & 5 \\
\hline 1722 & thiophene carboxaldéhyde & MS, RI & grilled, cooked & 5 & $2^{f}$ & 5 \\
\hline 1730 & 4-éthyl-benzaldéhyde & MS, RI, standard & minty, anisy & 5 & 6 & 4 \\
\hline 1740 & unidentified & & grilled & $2^{f}$ & $1^{\mathrm{f}}$ & 3 \\
\hline 1760 & 2-acétyl-2-thiazoline & MS, RI, odour ${ }^{\mathrm{e}}$ & $\begin{array}{l}\text { grilled hazel nut, } \\
\text { pop corn }\end{array}$ & 8 & 7 & 8 \\
\hline 1830 & unidentified & & $\begin{array}{l}\text { No common } \\
\text { descriptor }\end{array}$ & 2 & 5 & 5 \\
\hline 1842 & unidentified & & zest, fruity & 1 & 3 & 1 \\
\hline 1897 & unidentified & & potato & 3 & 4 & 5 \\
\hline
\end{tabular}

${ }^{\mathrm{a}}$ Retention index on DB-Wax column. ${ }^{\mathrm{b}}$ Odour description as perceived by panellists during olfactometry. Identification based on coincidence of odour description by assessors with odour description of ${ }^{\mathrm{c}}$ authentic standards or with odour description reported in the literature. ${ }^{\mathrm{d}}$ Furia $(1980)^{43}$, e Sekiwa et al $(1997)^{44}$. ${ }^{\mathrm{f}}$ Compounds not significantly perceived by panellists. MS: Mass spectra 
Six compounds, (E,Z)-2,6-nonadienal, 1-nonanol, decanal (E)-2-nonenal, 2-octen-1-ol and octanal were nearly detected in the three extracts. $(E, Z)-2,6$-nonadienal was perceived by 6 judges in SO and LO extracts and by 5 judges in FO extracts. This compound which is characterized by a cucumber-like odour has been described as one odorous compounds in fish and other seafood products 9,10,15,16,31. According to Milo and Grosch ${ }^{37,38}$, (E,Z)-2,6nonadienal strongly contributes to the odour of trout and cod. Hirano et al ${ }^{16}$ described it in ayu as the most important odorous compound, contributing to the cucumber odour of this fish. It results from enzymatic degradation of n-3 PUFA, particularly 18:3n-3 and 22:5n-3, due to 12-lipoxygenase 11. It seems therefore surprising that this compound was perceived in the same way in extracts from trout muscle presenting very different contents in n-3 PUFA. However we can think that because of its very low detection threshold of (E,Z)-2-6nonadienal (0.05 ppb) 39, the level of n-3 PUFA and/or the lipoxygenase activity in the three groups of fish were sufficient to generate a quantity superior to the perception threshold of numerous judges. Octanal was detected by 4,3 and 5 judges in FO, SO and LO extract respectively. This compounds is mainly generated from 11-hydroperoxyde of oleic acid 34 of which level of trout muscle was near, whatever the diet. Decanal was perceived with a fresh and green odour by 4 judges in FO and LO extract and by 5 judges in SO extract. Decanal mainly derives from oxidation of oleic acid 28,33 whose proportion was near in muscle of trout whatever the diets. It has been previously reported as an odour active compound in turbot fed diets containing soybean and linseed oil 17. 2-nonenal and 2-octen-1-ol are produced by n-6 PUFA oxidation 33. However although the n-6 PUFA content was higher in muscle of trout fed LO and SO diets than in those of trout fed a diet FO their perception by the jury was near or identical some either the diet. The lack of relation between the perception of some odorous compounds produced by fatty oxidation and the level of fatty acid in fish muscle could be explained by the principle of the oxidation mechanism. The initial step of the oxidative degradation of fatty acids involves the formation of an alkyl radical from unsaturated fatty acid ${ }^{12}$. Such radicals are formed much more readily from PUFA such as 22:6 n-3, 22:5 n-3 20:4 n-6, 20:5 n-3 than from 18:2 n-6 and 18:1 n-9. Once radicals are formed, propagation of the breakdown of other fatty acid molecules occurs via a chain reaction. In high PUFA meat, autoxidation of the fatty acids was initiated more readily by the presence of higher quantities of 18:3 n-3, 20:5 n-3 and 22:6n-3 and after initial step, the subsequent chain reaction was less dependent of the unsaturated substrate ${ }^{12}$. Hence in muscle of in the muscle of trout fed diet FO the high level of 22:6 n-3, 22:5 n-3 and 20:5 n-3 could favour the formation of breakdown products of n-6 PUFA (of 2-octen-1-ol, (E)-2-nonenal, (E)-2-heptenal) or of monounsaturated fatty acid (octanol).

Other odorous compounds perceived in the three extracts are generated by mechanisms different of fatty acid oxidation. 2-actyl-2-thiazoline, thiophene carboxaldéhyde, ethylpyrazine are generally considered to be thermally generated 40. However the extraction did not put in thermal treatment. Methional perceived by panellists with a boiled potato-like odour can be thermally induced but could be formed at low temperature from Strecker degradation of methionine induced by dicarbonyls compounds occurring during fatty acid oxidation 41,42. The perception of these compounds seems to be not related to experimental diets.

\section{Conclusions}

Results of olfactometric analysis show that the most of odorant perceived in all extracts are generated by unsaturated fatty acid oxidation. (E)-2-penten-1-ol, (E)-3-hexen-1-ol and (E)-2pentenal are perceived with the same highest intensity in all extracts. The perception of some 
compounds seems to be related to fatty acid content of muscle. (E,Z)-2,4-heptadienal generated by n-3 PUFA oxidation seems to strongly contribute to the odor of fillet of trout fed diets containing high levels of n-3 PUFA (fish oil and linseed oil). Hexanal, which comes from n-6 PUFA oxidation was significantly perceived by panellists only in extracts from trout fed diets with soybean oil or linseed oil. However the relationship between the perception of some compounds ( $(E)$-2-heptenal, octanol, 2-octen-1-ol, $(E)$-2-nonenal....) generated by fatty acid oxidation and fatty acid content of trout muscle is not easily to explain. In fact the perception of most odorous compounds could be more related to muscle level of polyunsaturated fatty acid than to its fatty acid composition. High level of PUFA involves a readily initiation of oxidation, allowing formation of breakdown products of less unsaturated fatty acids.

\section{Références}

1. Reinitz GL and Yu TC, Effects of dietary lipids on growth and fatty acid composition of rainbow trout (Salmo gairdneri). Aquaculture, 35: 19-27 (1981).

2. Greene DHS, Selivonchick DP, Effects of dietary vegetable, animal and marine lipids on muscle lipid and hematology of rainbow trout (Oncorhynchus mykiss). Aquaculture 89: 165-182 (1990).

3. Arzel J, Martinez-Lopez FX, Métailler R, Stéphan G, Viau M, Gandemer G and Guillaume J, Effect of dietary lipid on growth performance and body composition of brown trout (Salmo trutta) reared in seawater. Aquaculture 123: 361-375 (1994).

4. Skonberg D I, Rasco BA and Dong FM, Fatty acid composition of salmonid muscle change in response to a high oleic acid diet. J. Nutr 124: 1628-1638 (1993).

5. Boggio S, Hardy RW, Babitt J and Brannon E, The influence of dietary lipid source and alpha -tocopheryl acatate level on product quality of rainbow trout (Salmo gairdneri). Aquaculture 51: 13-24 (1985).

6. Skonberg D I, Rasco B A and Dong F M, Effect of feeding high monounsaturated sunflower oil diets on sensory attributes of salmonid fillets. J Aquat Food Prod Techn 2: 117-133 (1993).

7. Guillou A, Soucy P, Khalil M and Adambounou L, Effects of dietary vegetable and marine lipid on growth, muscle fatty acid composition and organoleptic quality of flesh of brook charr (Salvelinus fontinalis). Aquaculture 136: 351-362 (1995)..

8. Waagboo R, Sandnes K, Torrissen OJ, Sandvin A and Lie O, Chemical and sensory evaluation of fillets from Atlantic salmon (Salmo salar) fed three levels of n-3 polyunsaturated fatty acids at two levels of vitamin E. Food Chem 46: 361-366 (1993).

9. Josephson D B, Mechanisms for the formation of volatiles in fresh seafood flavors. Ph.D. thesis, University of Wisconsin- Madison 422 p (1987).

10. Prost $\mathrm{C}$, Serot $\mathrm{T}$ and Demaimay M, Identification of the most potent odorants in wild and farmed turbot. J Agric Food Chem 46: 3214-3219 (1998).

11. Josephson D B, Seafood, in Volatile compounds in Foods and Beverages, Maarse, H., Ed by Marcel Dekker, INC pp 179-202 (1991).

12. Elmore JS, Mottram DS, Enser M and Wood JD, Effect of the polyunsaturated fatty acid composition of beef muscle on the profile of aroma volatiles. J Agric Food Chem 47: 1619-1625 (1999). 
13. Larick DK, Hedrick HB, Bailey ME, Williams JE, Hancock DL, Garner GB and Morrow RE, Flavor constituents of beef as influenced by forage- and grain-feeding. $\mathrm{J}$ Food Sci 52: 245-251 (1987).

14. Larick DK,and Turner BE, Flavor constituents of beef as influenced by phospholid and fatty acid compositional differences. J Food Sci 55: 312-317 (1990).

15. Suyama M, Hirano T and Yamasaki S. Odour of Ayu and its volatile components. Bull Japan Soc Sci Fish 51: 287-294 (1985).

16. Hirano T, Zhang C H, Morishita A, Susuki T and Shirai T. Identification of volatile compounds in Ayu fish and its feeds, Nippon Suisan Gakkaish 58 : 547-557 (1992).

17. Serot T, Regost C, Prost C, Robin J and Arzel J, Effect of dietary lipid sources on odour -active compounds in muscle of turbot (Psetta maxima) J Sci Food Agric (2001).

18. Folch J, Lees M, Sloane Stanley G.H, A simple method for the isolation and purification of total lipides from animal tisues. J Biol Chem 226: 497-509 (1957).

19. Morrison W R and Smith L M, Preparation of fatty acid methyl esters and dimethyl acetals from lipids with boron fluoride-methanol. J. Lipid Research 5: 600-608 (1964).

20. Forss D A and Holloway G L, Recovery of volatile compounds from butter oil. J Am Oil Chem Soc 44: 572-575 (1967).

21. Etievant $\mathrm{P} X$ and Bayonove CL, Aroma components of pomace and wine from the variety Muscat de Frontignan. J Sci Food Chem 34: 393-403 (1983).

22. Moio L, Chambellan E, Lesscaeve I, Issanchou S, Schlich P and Etievant P X, Production of representative wine extract for chemical and olfactory analysis. Ital $\mathrm{J}$ Food Sci 3: 265-277 (1995).

23. Etievant PX, Moio L, Guichard E, Langlois D, Leschaeve I, Schlich P and Chambellan E, Aroma extract dilution analysis (AEDA) and the representativeness of the odour of food extracts, in Trends in flavour research, ed by Maarse $\mathrm{H}$ and van der Heij DG. Elsevier Science B.V. pp 179-190 (1994).

24. Charles M, Martin B, Ginies C, Etievant P, Coste G and Guichard E, Potent aroma compounds of two red wine vinegars. J Agric Food Chem 48: 70-77.

25. Escudero A and Etievant P, Effect of antioxidants on the flavor characteristics and the gas chromatography/olfactometry profiles of champagne extracts. J Agric Food Chem 47: 3303-3308.

26. Van den Dool H Kratz P D, A generalization of the retention index system including linear temperature programmed gas-liquid partition chromatography. J Chromatogr 11: 463 (1963).

27. Pollien P, Ott A, Montignon F, Baumgartner M, Munoz-Box R and Chaintreau A, Hyphenated headspace-gas chromatography-sniffing technique: screening of impact odourants and quantitative aromagram comparisons. J Agric.Food Chem 45: 26302637 (1997).

28. Grosch W, Reactions of hydroperoxydes-products of low molecular weight, in Autooxidation of unsaturated lipids, Ed by Chan H. W. S. Academic Press, London, 95-139 (1987).

29. Tanchotikul U and Hsieh T C Y, Volatile flavor components in crayfish waste. J Food Sci 54: 1515-1520 (1989).

30. Josephson D B, Lindsay R C, Retro-aldol degradations of unsaturated aldehydes : Role in the formation of c4-heptenal from t2, c6-nonadienal in fish, oyster and other flavors. JAOCS 64: 1 132-138 (1987). 
31. Tanchotikul U and Hsieh T C, Analysis of volatile flavor components in steamed rangia clam by dynamic headspace sampling and simultaneous distillation and extraction. J Food Sci 56: 327-331 (1991).

32. Le Guen S Prost C and Demaimay M, Critical comparison of three olfactometric methods for the identification of the most potent odourants in cooked mussels (Mytilus edulis). J Agric Food Chem 48: 1307-1314 (2000).

33. Hsieh R J and Kinsella J E, Oxydation of polyunsaturated fatty acids : mechanisms, products and inhibition with emphasis on fish. Adv Food Nutr Res 33: 233-341 (1989).

34. Frankel E.N, Volatile lipid oxidation products. Prog. Lip. Res. 22: 1-33 (1982).

35. Sahidi F and Pegg R B, Hexanal as an indicator of the flavor deterioration of meat and meat products, in Seafood chemistry proceeding technology and quality, Ed by Blakie academic and professional, Glasgow, pp 34-48 (1994).

36. St.Angelo A J, Lipid oxidation in foods. Crit Rev Food Sci Nutr 36: 175-224 (1996).

37. Milo C and Grosch W, Detection of odour defects in boiled cod and trout by gas chromatography-olfactometry of headspace samples. J Agric Food Chem 43: 459-462 (1995).

38. Milo C and Grosch W, Changes in the odorants of boiled salmon and cod as affected by the storage of the raw material. J Agric Food Chem 44: 2366-2371 (1996).

39. Leffingwell J C and Leffingwell D, GRAS Flavor Chemicals-Detection Threshold. Perfumer \& Flavorist 16: 1-19 (1991).

40. Le Guen S, Prost C, Demaimay M, Characterization of odorant compounds of mussels (Mytilus edulis) according to their origin using gas chromatographyolfactometry and gas chromatography-mass spectrometry. J Chromatogr A 896 : 361371 (2000).

41. Pripis-Nicolau L, de-Revel G, Bertrand A and Maujean A, Formation of flavor components by the reaction of amino acid and carbonyl compounds in mild conditions. J Agric Food Chem 48: 3761-3766 (2000).

42. Marchand S, de Revel G and Bertrand A, Approaches to wine aroma: Release of aroma compounds from reactions between cysteine and carbonyl compounds in wine. J Agric Food Chem 48: 4890-4895 ( 2000).

43. Furia T E, CRC Handbook of Food Additives $2^{\text {nd }}$ Ed by CRC Press :Boca Raton, FL, Vol II, pp 259-316 (1980).

44. Sekiwa Y, Kubota K, Kobayashi A, Characteristic flavor components in the brew of cooked clam and the effect of storage on flavor formation. J Agric Food Chem 45: 826-830 (1997). 